Supplement of Earth Syst. Dynam., 12, 313-326, 2021

https://doi.org/10.5194/esd-12-313-2021-supplement

(c) Author(s) 2021. This work is distributed under

the Creative Commons Attribution 4.0 License.

(c) (1)
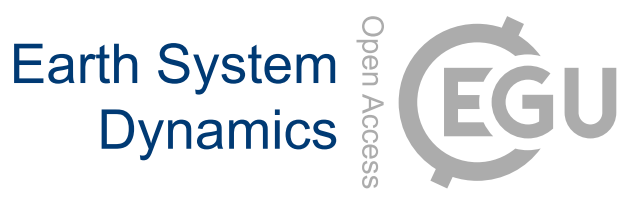

Supplement of

\title{
The response of terrestrial ecosystem carbon cycling under different aerosol-based radiation management geoengineering
}

Hanna Lee et al.

Correspondence to: Hanna Lee (hanna.lee@norceresearch.no)

The copyright of individual parts of the supplement might differ from the CC BY 4.0 License. 
Figure S1: Distribution of dominant biomes on land used in this study.

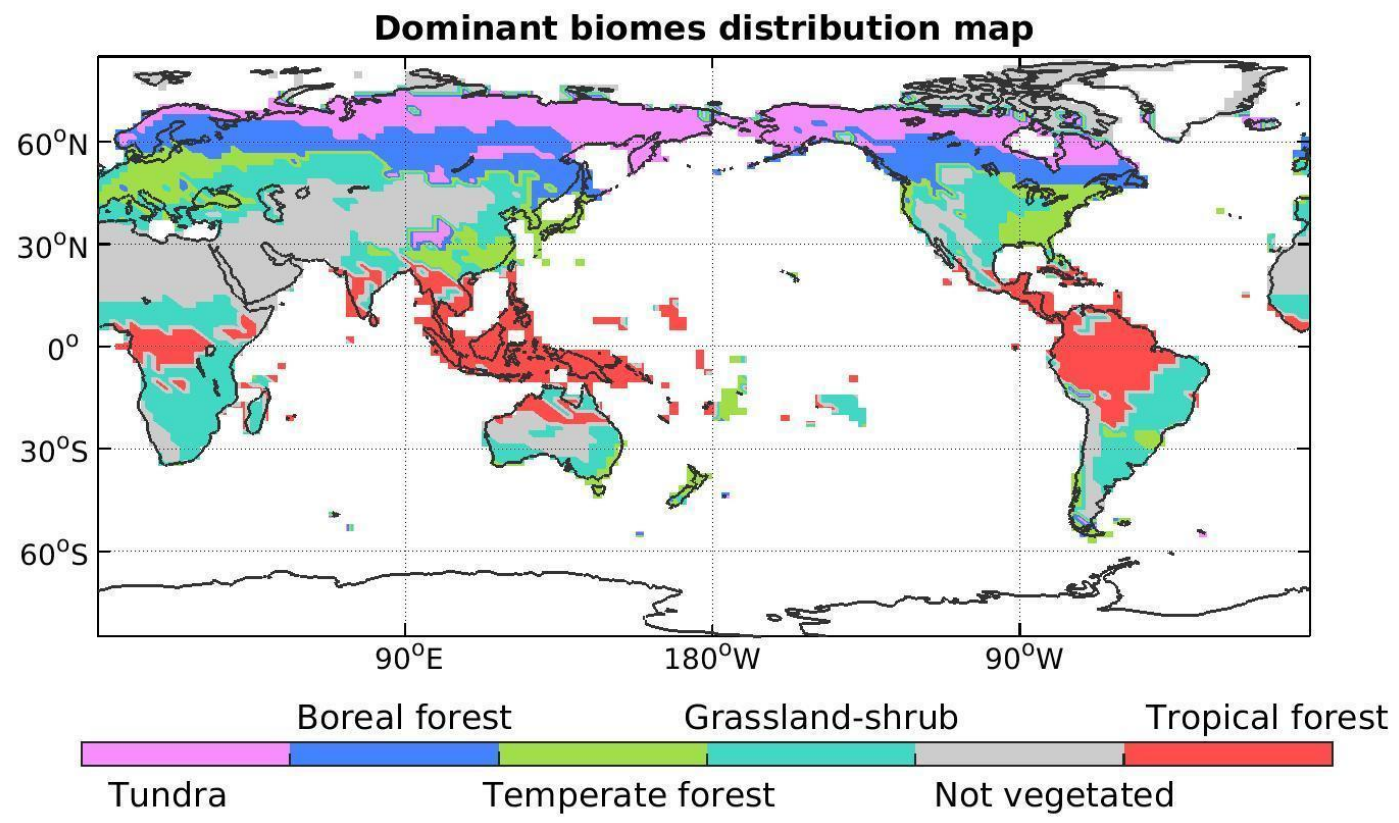


Figure S2: The deviation of DVR, FVR, and TSA, simulated by the three RM methods relative to the baseline RCP8.5 scenario. The values shown here are the mean difference of the 2070-2100 time period and the mean over three ensemble members.
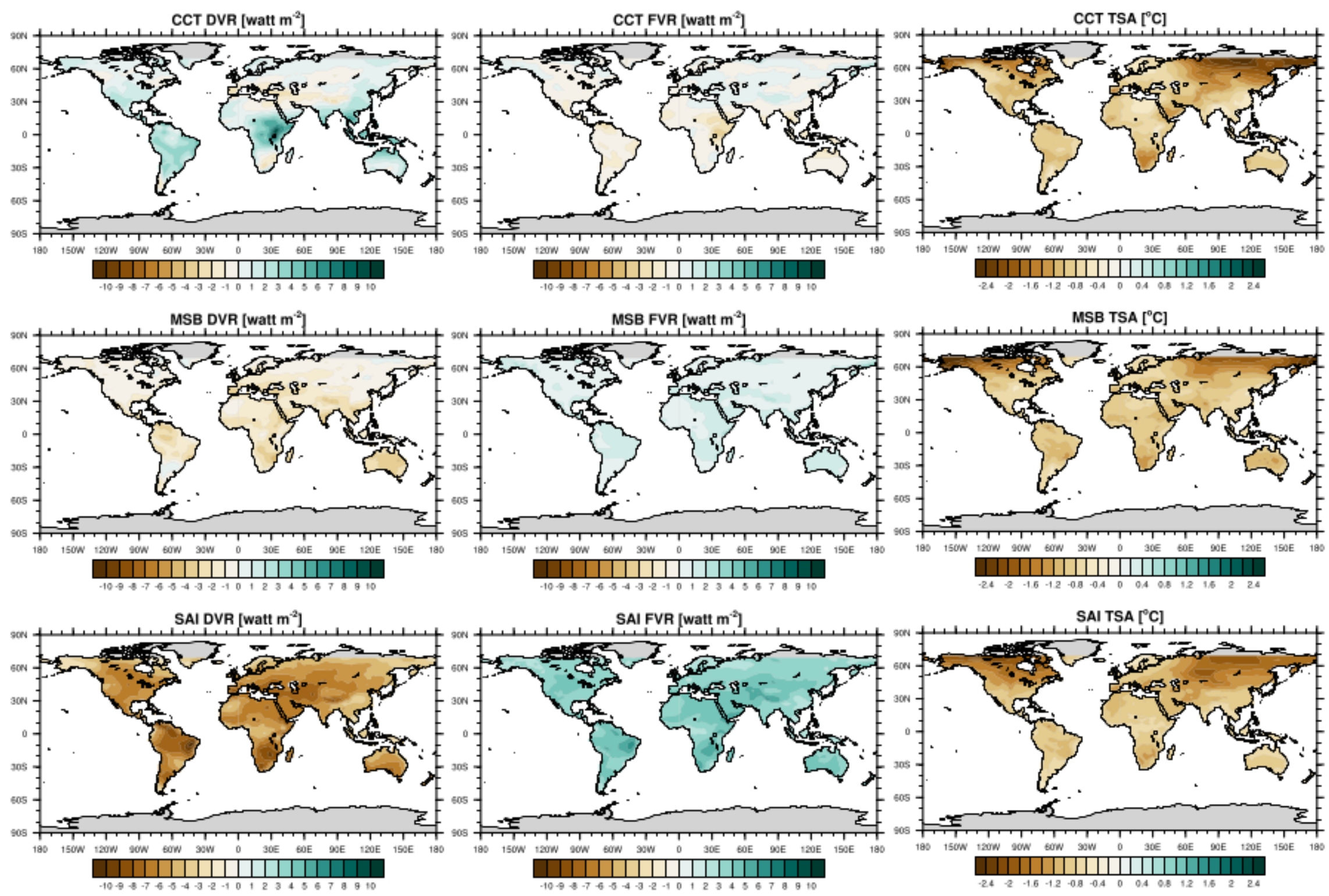
Figure S3: Spatial pattern of temporal correlation between the simulated results between RCP8.5 and the RM methods based on RCP8.5 scenario. The correlations shown are FVR-NPP, TSA-NPP, precipitation-NPP in each grid of the model mean over the 2070-2100 period.
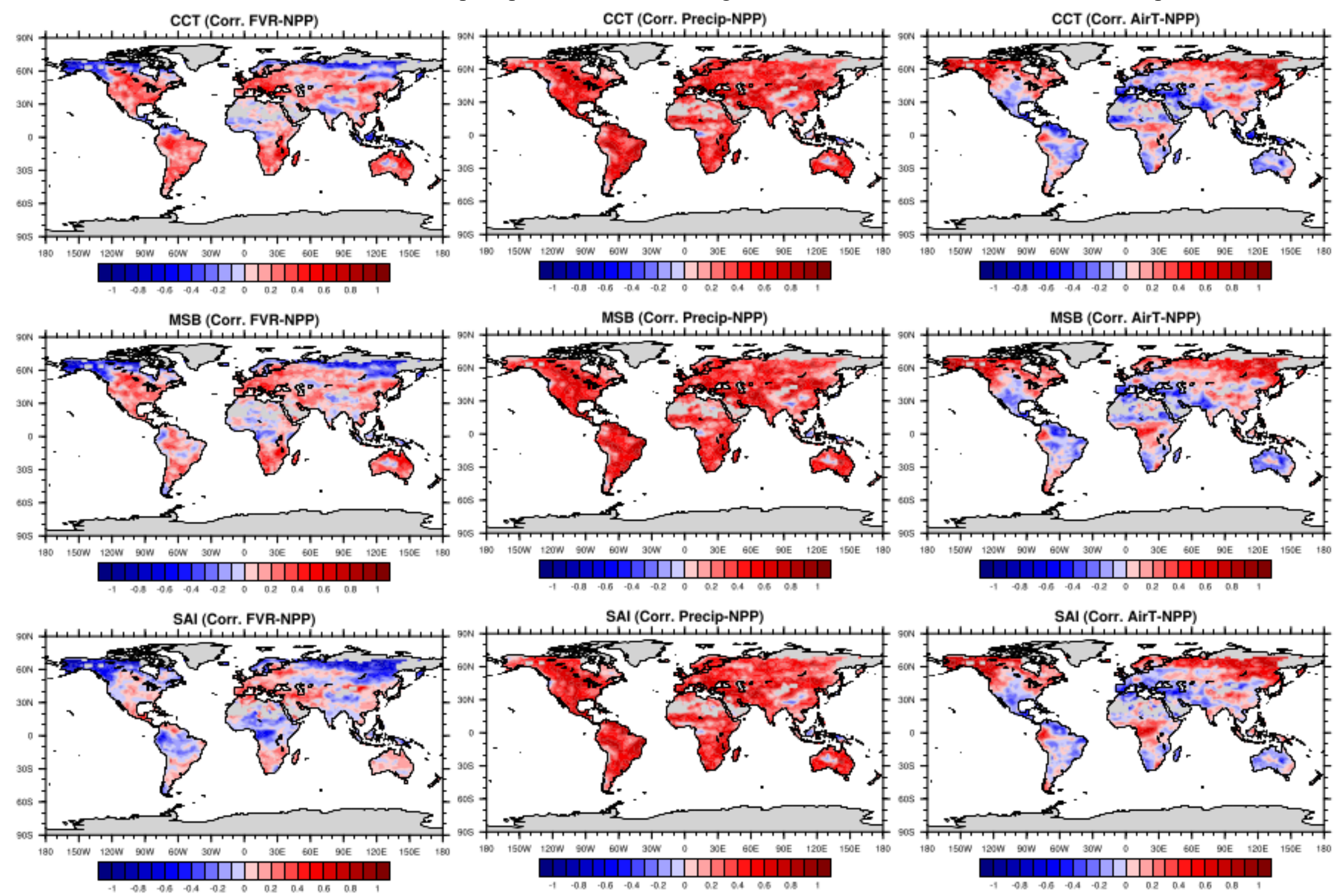
Figure S4: Monthly climatology showing seasonality change in rain and air temperature under RCP4.5, RCP8.5, CCT, MSB, and SAI simulations. The values shown here are biome mean in the 2070-2100 time period.
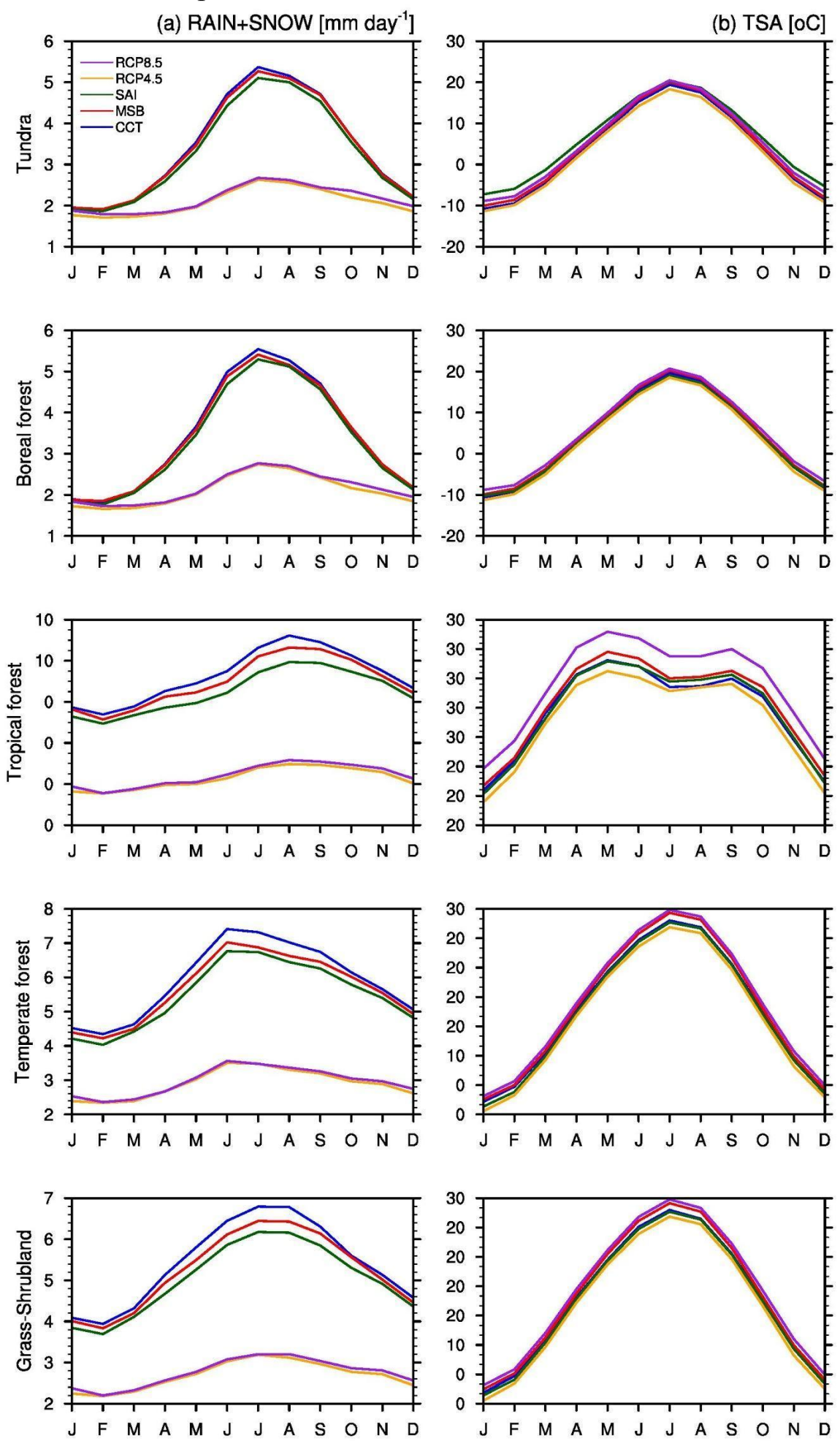
Figure S5: Monthly climatology showing seasonality change in NPP and LAI under RCP4.5, RCP8.5, CCT, MSB, and SAI simulations. The values shown here are biome mean in the 2070-2100 time period.

(a) NPP $\left[\mathrm{gC} \mathrm{m}^{-2}\right.$ month $\left.^{-1}\right]$
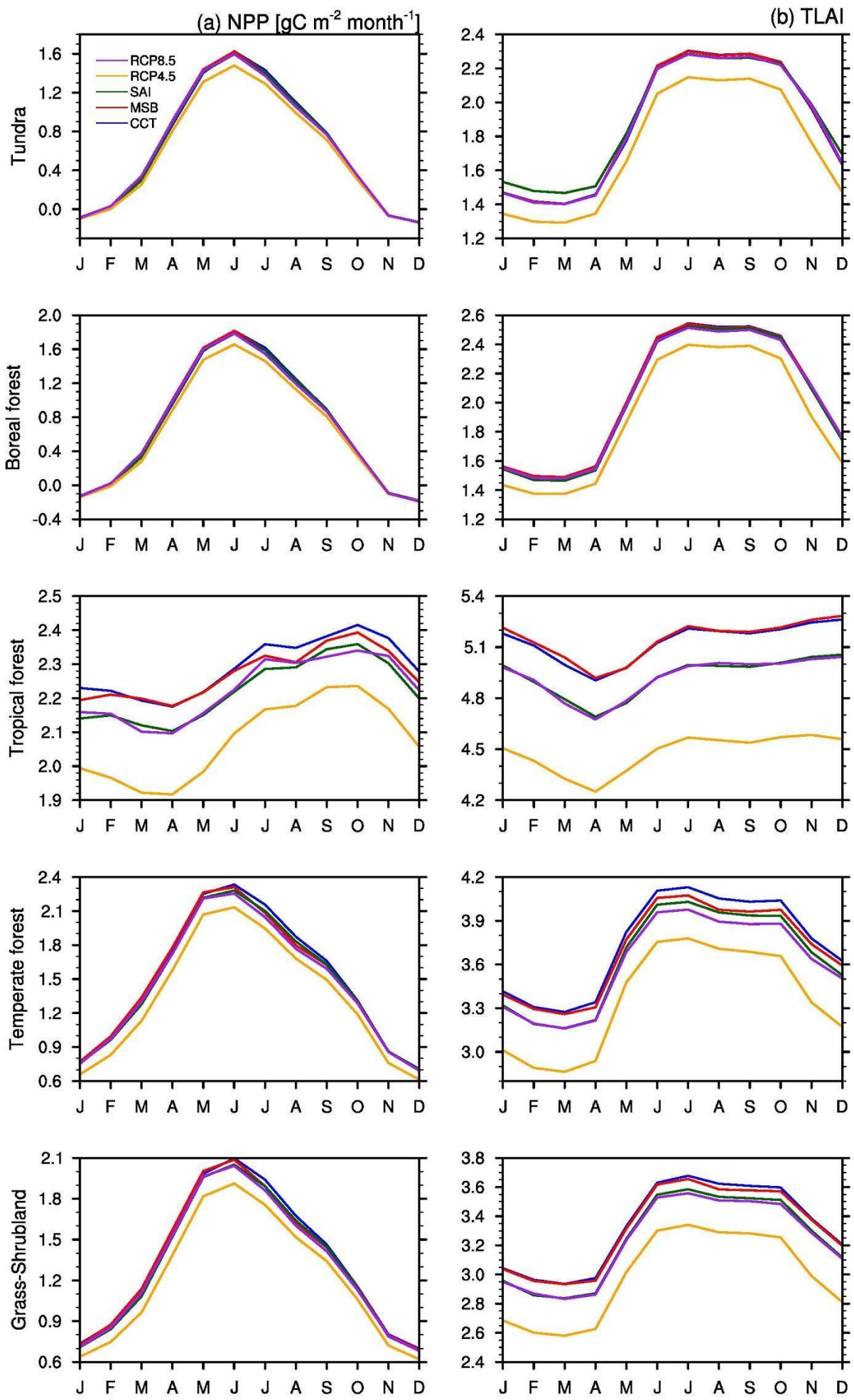
Figure S6: The relative difference in total vegetation and soil carbon between the RM to RCP8.5 scenario. The values shown here are biome mean.
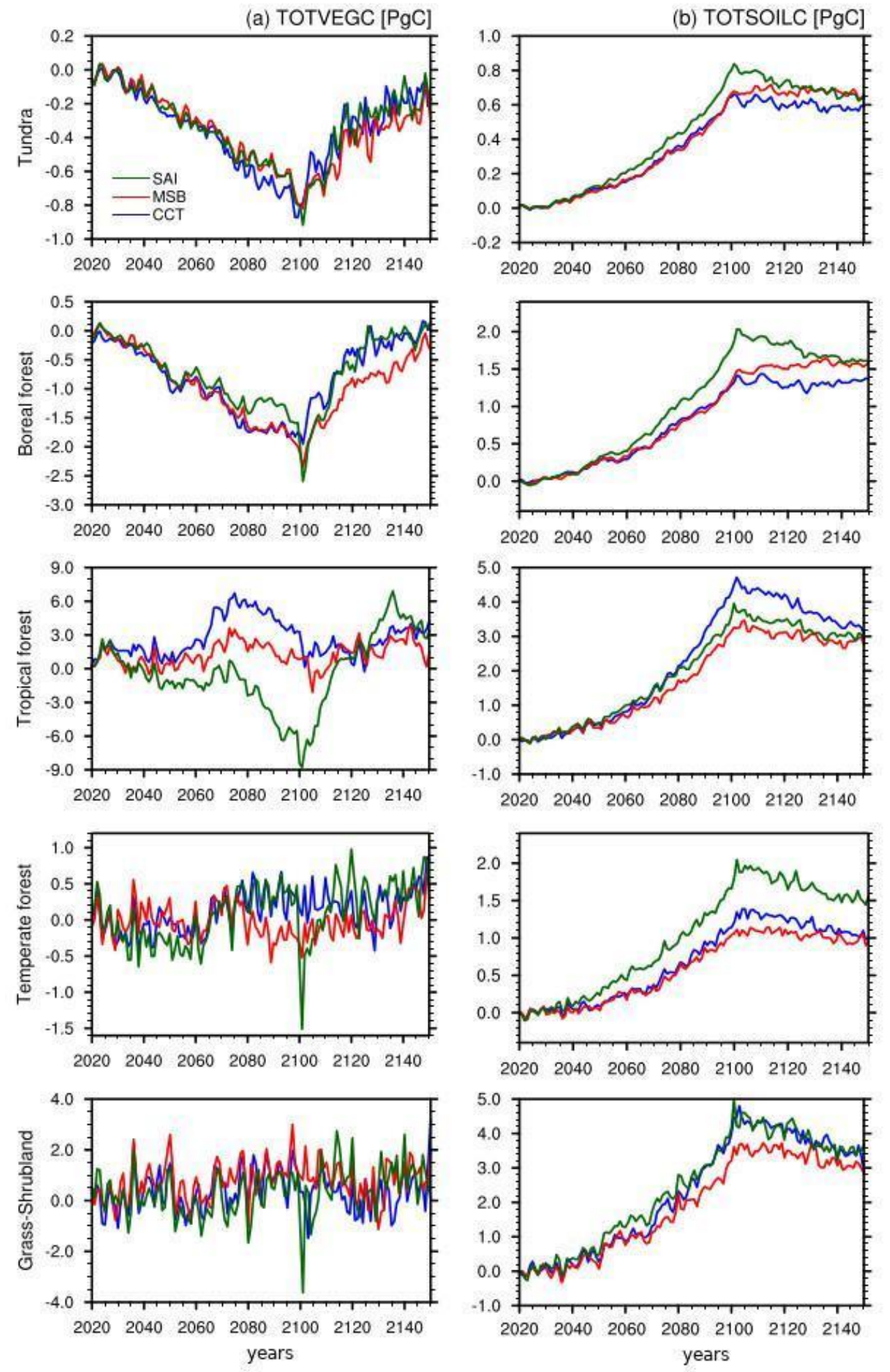
Figure S7: Global vegetation and soil C storage. The values shown here are -60 to $70^{\circ} \mathrm{N}$ sum from the land area.

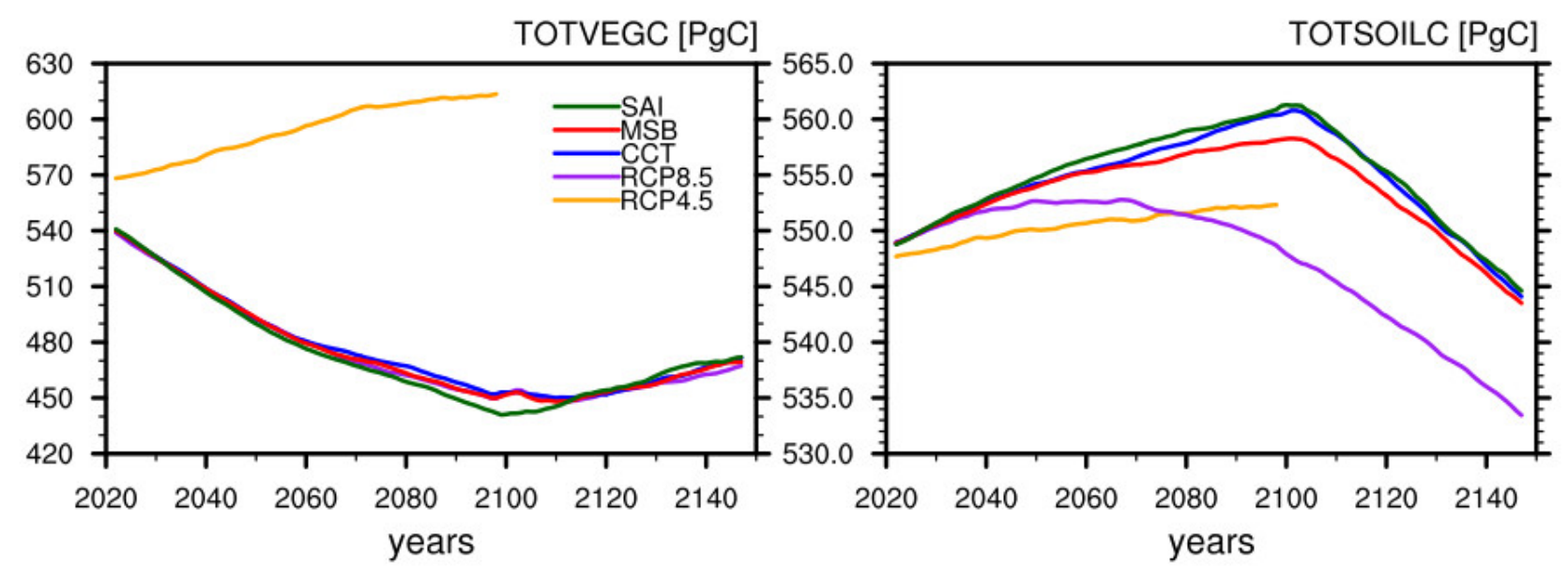

